\title{
Glyphosate induces immune dysregulation in honey bees
}

\author{
Erick V. S. Motta* ${ }^{*}$, J. Elijah Powell and Nancy A. Moran*
}

\begin{abstract}
Background: Similar to many other animals, the honey bee Apis mellifera relies on a beneficial gut microbiota for regulation of immune homeostasis. Honey bees exposed to agrochemicals, such as the herbicide glyphosate or antibiotics, usually exhibit dysbiosis and increased susceptibility to bacterial infection. Considering the relevance of the microbiota-immunity axis for host health, we hypothesized that glyphosate exposure could potentially affect other components of the honey bee physiology, such as the immune system.

Results: In this study, we investigated whether glyphosate, besides affecting the gut microbiota, could compromise two components of honey bee innate immunity: the expression of genes encoding antimicrobial peptides (humoral immunity) and the melanization pathway (cellular immunity). We also compared the effects of glyphosate on the bee immune system with those of tylosin, an antibiotic commonly used in beekeeping. We found that both glyphosate and tylosin decreased the expression of some antimicrobial peptides, such as apidaecin, defensin and hymenoptaecin, in exposed honey bees, but only glyphosate was able to inhibit melanization in the bee hemolymph.
\end{abstract}

Conclusions: Exposure of honey bees to glyphosate or tylosin can reduce the abundance of beneficial gut bacteria and lead to immune dysregulation.

Keywords: Honey bees, Glyphosate, Tylosin, Humoral immunity, Cellular immunity, Microbiome

\section{Background}

A well-balanced gut microbiota is usually associated with positive benefits to host health including digestion of recalcitrant components of the diet, production of nutrients (e.g., short-chain fatty acids), regulation of immune homeostasis and protection against opportunistic pathogens [1]. Therefore, imbalances to the gut microbiota, commonly called dysbiosis, may lead to various negative consequences to hosts, culminating in poor development, immune dysregulation and disease [2]. These effects occur in many animals, including the Western honey bee, Apis mellifera, an important agricultural pollinator that relies on a beneficial gut microbiota to maintain homeostasis [3-5]. The honey bee gut microbiota

*Correspondence: erickvsm@utexas.edu; nancy.moran@austin.utexas.edu Department of Integrative Biology, University of Texas at Austin, 2506 Speedway, Austin, TX 78712, USA is dominated by 5 to 8 host-restricted bacterial lineages; this community fully colonizes the bee gut within 5 days after emergence and remains compositionally stable until a bee become a forager and is exposed to environmental microbes [3]. At emergence from the pupal stage, the bee digestive tract is devoid of microbes [6]. Experiments using gnotobiotic honey bees have demonstrated the importance of the native gut microbiota, including the contribution of specific bacterial members, such as Snodgrassella alvi and Frischella perrara, to the stimulation and regulation of the immune system [7-9].

Honey bees have a robust innate immune system that, along with physical barriers (e.g., exoskeleton cuticle, peritrophic membranes lining the midgut and microbial biofilms on the hindgut wall), plays a major role in protection against opportunistic bacteria, fungi and parasites $[7,8,10]$. Honey bee innate immunity is divided into two main categories: humoral and cellular immunity [11]. original author(s) and the source, provide a link to the Creative Commons licence, and indicate if changes were made. The images or other third party material in this article are included in the article's Creative Commons licence, unless indicated otherwise in a credit line to the material. If material is not included in the article's Creative Commons licence and your intended use is not permitted by statutory regulation or exceeds the permitted use, you will need to obtain permission directly from the copyright holder. To view a copy of this licence, visit http://creativecommons.org/licenses/by/4.0/. 
Humoral immunity involves the production of antimicrobial peptides (AMPs), such as abaecin [12], apidaecin [13], defensin [14] and hymenoptaecin [15], which are released by host cells in response to infection by opportunistic pathogens [10]. Cellular immunity involves processes such as phagocytosis, nodulation and encapsulation, these last two being often accompanied by melanization, a process commonly catalyzed by phenoloxidases that leads to the production of several reactive quinones (e.g., dopachrome) and ultimately melanin, which are very toxic to microbes $[16,17]$.

Honey bees exposed to antibiotics exhibit dysbiosis and increased susceptibility to opportunistic bacterial pathogens $[18,19]$. More recent studies have demonstrated that other anthropogenic chemicals, such as glyphosate, can also perturb the gut microbiota of honey bees [2024]. Similar cases of dysbiosis have also been observed in other non-target organisms exposed to glyphosate or glyphosate-based formulations [25-30], raising concerns regarding whether glyphosate-induced dysbiosis could affect host immune homeostasis.

Glyphosate is a broad-spectrum herbicide with bacteriostatic properties globally used to destroy unwanted vegetation in crop and non-crop areas and applied at concentrations usually higher than $30 \mathrm{mM}$ (see reference [31] for details regarding glyphosate's mechanism of action). Besides the effects on the gut microbiota, glyphosate has been also associated with behavioral, developmental and/ or neurological changes in honey bee larvae, honey bee adults [32-38] and other non-target organisms [39-41]. Glyphosate can also inhibit melanization in fungi [42] and in the hemolymph of some insects [43].

In this study, we investigated whether glyphosate exposure affects the honey bee immune system. Towards this goal, we performed a series of experiments to investigate the effects of glyphosate on the expression of host immunity-related genes and on the melanization cascade. First, we performed three in vivo experiments in which honey bees were exposed to sublethal concentrations of glyphosate. These experiments were performed in different seasons. In the first two in vivo experiments, we investigated changes in gene expression in gut tissues, whereas in the third in vivo experiment, we extended our assays to whole bee body samples. Second, we conducted ex vivo and in vivo experiments in which bee hemolymph and honey bees, respectively, were exposed to different concentrations of glyphosate to investigate potential consequences for the melanization cascade, an important component of bee immunity.

In all experiments, we included a negative control group (no glyphosate exposure), and an antibiotic-treated comparison group. Antibiotics are known to affect the gut microbiota and the expression of immunity genes in honey bees $[18,19,44,45]$, and this comparison enabled us to verify that our methods were able to detect these shifts. For that comparison group, we used tylosin, an antibiotic commonly used in beekeeping [46] and also known to perturb the gut microbiota of honey bees [21, 22]. Finally, we assayed cultivated bee bacterial pathogens for their susceptility to bee antimicrobial peptides that we found to be affected by glyphosate exposure. Below, we describe these experiments in detail.

\section{Results \\ Effects of glyphosate and tylosin on the transcriptome and microbiome of honey bees}

Considering that glyphosate or tylosin exposure affects the gut microbiota of honey bees [20-24], we decided to investigate whether these microbial perturbations could lead to other impacts on honey bee physiology. To address this, we initially investigated changes in the honey bee gut transcriptome due to glyphosate ( 0.1 or $1 \mathrm{mM})$ or tylosin $(0.1 \mathrm{mM})$ exposure in experiments performed in fall 2018 and summer 2020 (Fig. 1). For that, RNA was extracted from the guts of 15 bees from each group in each experiment, then pooled in groups of three, giving a total of five pooled samples per group. These samples were submitted for $3^{\prime}$-Tag RNA sequencing, an alternative method for conventional RNA sequencing, which focuses sequencing effort on the $3^{\prime}$ end of mRNAs, reducing sequencing depth per sample, and thus cost [47]. In the fall 2018 experiment, we observed a downregulation for the gene encoding the antimicrobial peptide hymenoptaecin (LOC406142) in the guts of glyphosate- or tylosin-exposed bees when compared to unexposed bees (Fig. 2). The gene encoding a Toll-like receptor 4 (LOC724187) was also downregulated in the guts of glyphosate-exposed bees (Fig. 2A, B). Also, the genes encoding apidermin 2 (Apd-2), an odorant binding protein 21 (Obp21), and a purine nucleoside phosphorylase (LOC408299) were upregulated in the guts of tylosin-exposed bees (Fig. 2C). However, these effects were not observed in the summer 2020 experiment, for which we only detected a few significantly downregulated genes in the guts of $1 \mathrm{mM}$ glyphosate-exposed bees, which encoded a chemosensory protein 1 (CSP1), a phospholipase A2-like (LOC724436), and an unknown protein (LOC100577054) (Additional file 1: Fig. S1). To further investigate the results obtained in the fall 2018 experiment, we used individual RNA samples from control and specific treatment groups as templates for RT-qPCR, giving a total of 15 samples per group, and checked the expression of genes encoding hymenoptaecin (Fig. 2D) and Toll-like receptor 4 (Fig. 2E). Based on the RT-qPCR assays, we found significantly 


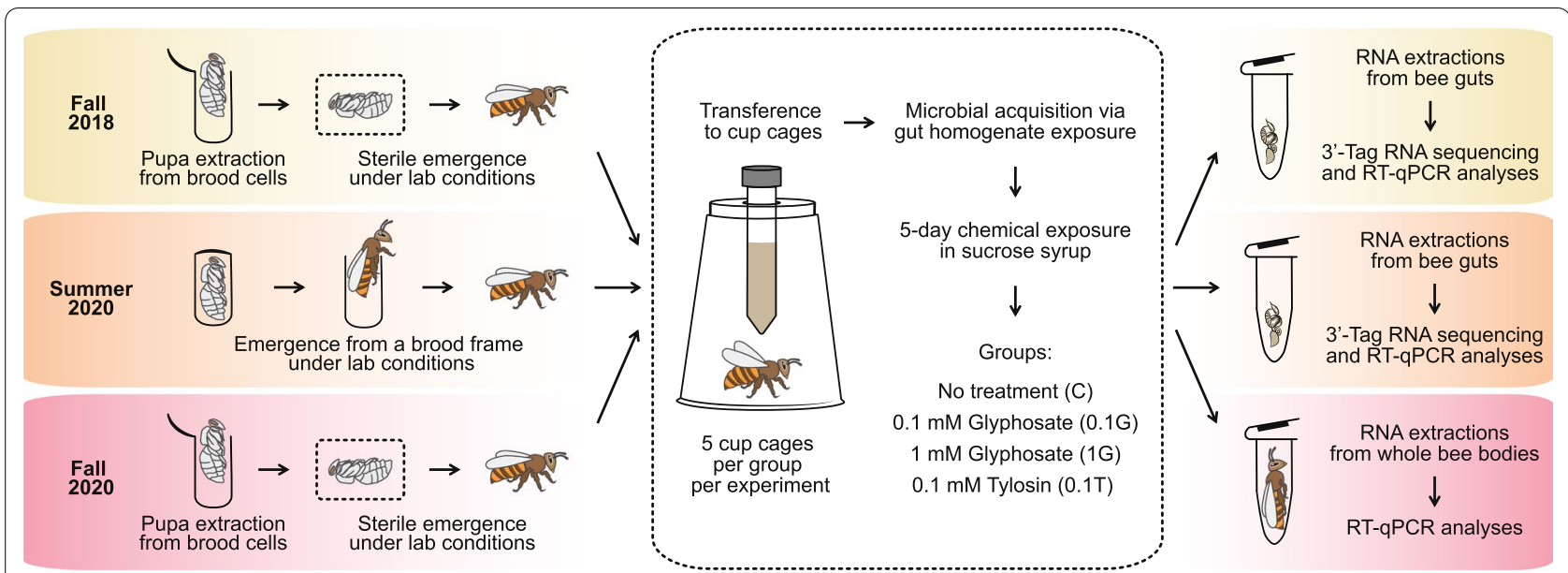

Fig. 1 In vivo experiments to investigate the effects of glyphosate and tylosin on the honey bee immune system. Three independent experiments were performed with newly emerged honey bees (Apis mellifera) originating from different hives from different seasons. In the fall 2018 and fall 2020 experiments, pupae were extracted from a brood frame and allowed to emerge under sterile conditions, whereas in the summer 2020 experiment, pupae were allowed to emerge naturally from a brood frame kept in the laboratory. In all experiments, healthy newly emerged workers were transferred to cup cages and allowed to acquire their microbiota simultaneously to treatment (0.1 mM glyphosate, 1 mM glyphosate or $0.1 \mathrm{mM}$ tylosin in sucrose syrup) for 5 days. A control group was treated with sucrose syrup only. In the fall 2018 and summer 2020 experiments, RNA was extracted from individual bee guts and pooled for 3'-Tag RNA sequencing (3 pooled guts per sample, 5 samples sequenced per group), whereas in the fall 2020 experiment, RNA was extracted from whole bee bodies (15 individual bees per group) and used in downstream analyses

lower expression for hymenoptaecin in gut tissues of the $0.1 \mathrm{mM}$ glyphosate-exposed group, with a 3.6-fold decrease, as well as nonsignificant decreases for both other treatment groups ( $1 \mathrm{mM}$ glyphosate and $0.1 \mathrm{mM}$ tylosin) (Fig. 2D). However, the RT-qPCR data for the Toll-like receptor 4 gene did not corroborate the findings observed in the $3^{\prime}$-Tag RNA-seq data, and thus we were unable to draw any conclusion regarding the impact of glyphosate on expression of this gene.

We also investigated perturbations in the gut microbiota caused by glyphosate or tylosin exposure in both experiments (Fig. 3 and Additional file 1: Fig. S2). For the fall 2018 experiment, we found results similar to those of previous studies [22]: significant decreases in $S$. alvi and Gilliamella spp. in glyphosate-exposed groups (Fig. 3A, B), and significant decreases in Bifidobacterium spp. and Lactobacillus Firm-4 and Firm-5 in the tylosinexposed group (Fig. 3C-E). However, fewer significant changes were observed for the summer 2020 experiment, with decreases in abundance only for $S$. alvi in the $1 \mathrm{mM}$ glyphosate-exposed group, and Bifidobacterium spp. in the $0.1 \mathrm{mM}$ tylosin-exposed group (Fig. 3 and Additional file 1: Fig. S2), suggesting that the greater the perturbation of the microbiome the greater the impact on the immune system. However, this is not conclusive, since these experiments were performed in slightly different ways (Fig. 1): experimental bees from the fall 2018 experiment came from late-stage pupae extracted from brood cells, while bees from the summer 2020 experiment were allowed to emerge naturally from brood frames kept in the laboratory.

To further explore the effects of glyphosate and tylosin on the bee humoral response and in other bee body compartments, we performed a third (fall 2020) experiment, in which we handled the bees similarly to the fall 2018 experiment, but extracted RNA from whole bee bodies, instead of only guts, and used these RNA samples as templates for RT-qPCR analyses (Fig. 1). We checked the expression of genes encoding the AMPs abaecin, apidaecin, defensin and hymenoptaecin, and found significant downregulations for apidaecin (4.4- and 3.7-fold decreases for the $1 \mathrm{mM}$ glyphosate and $0.1 \mathrm{mM}$ tylosin exposed groups, respectively), defensin-2 (2.4-, 3.7- and 2.7-fold decreases for the $0.1 \mathrm{mM}$ glyphosate, $1 \mathrm{mM}$ glyphosate and $0.1 \mathrm{mM}$ tylosin exposed groups, respectively), and hymenoptaecin (3.7-fold decrease for the $1 \mathrm{mM}$ glyphosate exposed group) (Fig. 4). The data collected from these three experiments demonstrate that glyphosate and tylosin can affect the immune system of honey bees, by changing the expression of AMPs, but this effect may vary according to tissue analyzed, experimental conditions or colony status.

A major question is whether changes in immune expression affects pathogen susceptibility and therefore contributes to the protective effect observed for the bee gut microbiota [48]. Thus, we investigated the susceptibility of an opportunistic pathogen of adult bees, Serratia marcescens, to apidaecin (isoforms $1 \mathrm{a}$ and $1 \mathrm{~b}$ ) and 

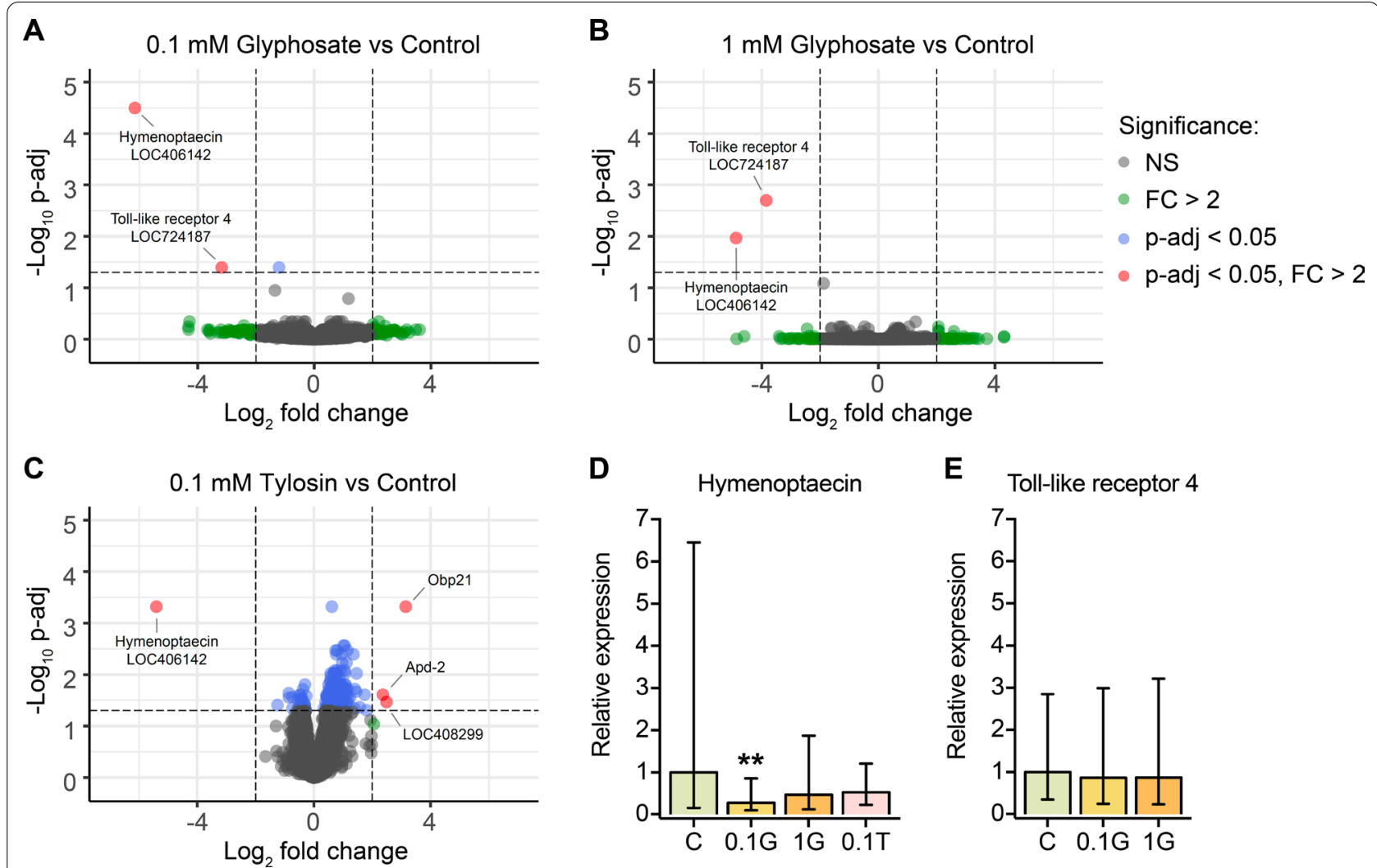

Fig. 2 Effects of glyphosate or tylosin exposure on the gut transcriptome of honey bees in fall 2018. A-C Volcano plots showing differential gene expression in the guts of bees exposed to $\mathbf{A} 0.1 \mathrm{mM}$ glyphosate, B $1.0 \mathrm{mM}$ glyphosate or $\mathbf{C} 0.1 \mathrm{mM}$ tylosin, when compared to unexposed, control bees, for a total of 9833 genes. Data points are colored for genes significantly differentially expressed, as follows: blue for $p$-adj $<0.05$, green for FC $>2$ and red for both $p$-adj $<0.05$ and FC $>2$; non-significant points are gray. Each group consists of 5 samples, each representative of 3 bee guts. D, E RT-qPCR expression for the genes $\mathbf{D}$ hymenoptaecin and $\mathbf{E}$ Toll-like receptor 4 relative to the housekeeping gene rps 5 in the guts of unexposed and 5 day exposed bees. Each group consists of 15 samples, each representative of a bee gut. Averages and standard deviations are shown as bars and error bars. The linear regression 'Im' option in the pcr package in R was applied to estimate differences between control and treatment groups. ${ }^{* *} p<0.01$

hymenoptaecin by performing minimum inhibitory concentration (MIC) assays. We tested four strains, Db11 [49], Ss1 [50], kz11 and kz19 [51], and none were inhibited by the AMPs $(\mathrm{MIC}>50 \mu \mathrm{g} / \mathrm{mL}$ ) (Additional file 1 : Fig. S3, Additional file 1: Table S2). In contrast, the bee gut symbiont $S$. alvi strain wkB2 was also tested and exhibited susceptibility to apidaecin $1 \mathrm{~b}(\mathrm{MIC}=25 \mu \mathrm{g} /$ $\mathrm{mL}$ ) and hymenoptaecin $(\mathrm{MIC}=12.5 \mu \mathrm{g} / \mathrm{mL}$ ) (Additional file 1: Fig. S3, Additional file 1: Table S2).

\section{Effects of glyphosate and tylosin on the melanization cascade of honey bees}

The main effects observed for the gut transcriptome and RT-qPCR data were associated with perturbations of the bee immune system, and a recently published study showed that glyphosate can inhibit melanization in the hemolymph of some insects [43]. Therefore, we decided to investigate whether glyphosate affects melanization in honey bees.

Initially, we examined the transcript level of the gene encoding prophenoloxidase, which is involved in the melanization immune response [11]. This gene did not show significant expression differences in guts of control and glyphosate-exposed bees in either the fall 2018 or summer 2020 experiments, based on the transcriptome data, nor in whole bee bodies in the fall 2020 experiment, based on the RT-qPCR data (Fig. 4E).

Then, we investigated the ability of glyphosate (and tylosin for comparison) to inhibit the formation of melanin or intermediates of the melanization cascade, as demonstrated for other insects [43]. We tested a wide range of concentrations (from 0.1 to $10 \mathrm{mM}$ ) in two different sets of experiments to make sure we would capture the potential effects of glyphosate (and tylosin) on the bee melanization cascade (Fig. 5). 

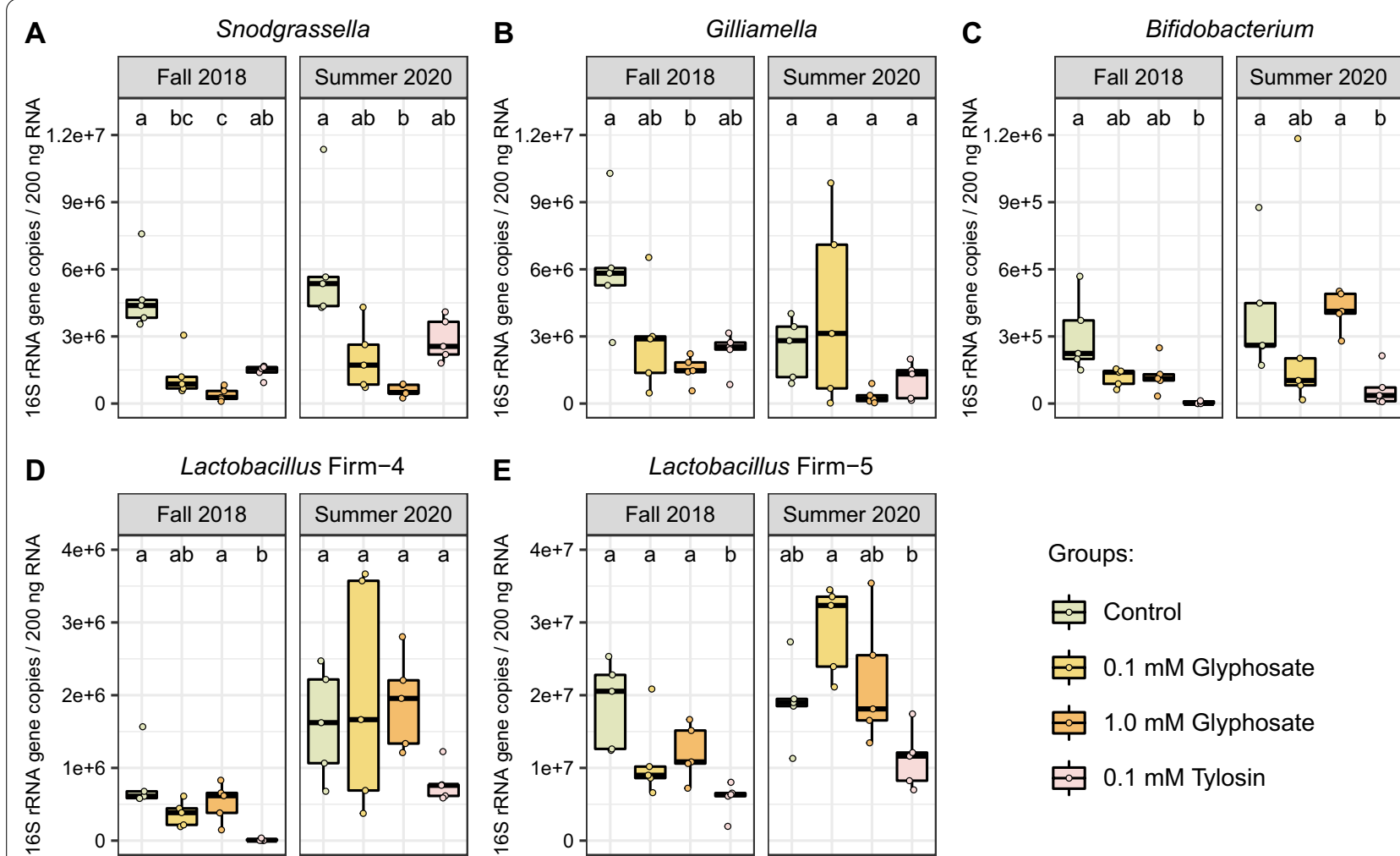

Fig. 3 Effects of glyphosate or tylosin exposure on the gut microbiota of honey bees in the fall 2018 and summer 2020 experiments. A-E Changes in the abundance of 165 rRNA gene transcripts for A Snodgrassella, B Gilliamella, C Bifidobacterium, D Lactobacillus Firm-4, and E Lactobacillus Firm- 5 in the guts of honey bees exposed to $0.1 \mathrm{mM}$ glyphosate, $1.0 \mathrm{mM}$ glyphosate or $0.1 \mathrm{mM}$ tylosin for 5 days, when compared to unexposed, control bees. Each group consists of 5 samples, each representative of 3 bee guts. Each experiment was analyzed individually, and significance of differences among groups was measured with Kruskal-Wallis tests followed by Dunn's multiple-comparison tests. Groups with different letters are significantly different at $p<0.05$

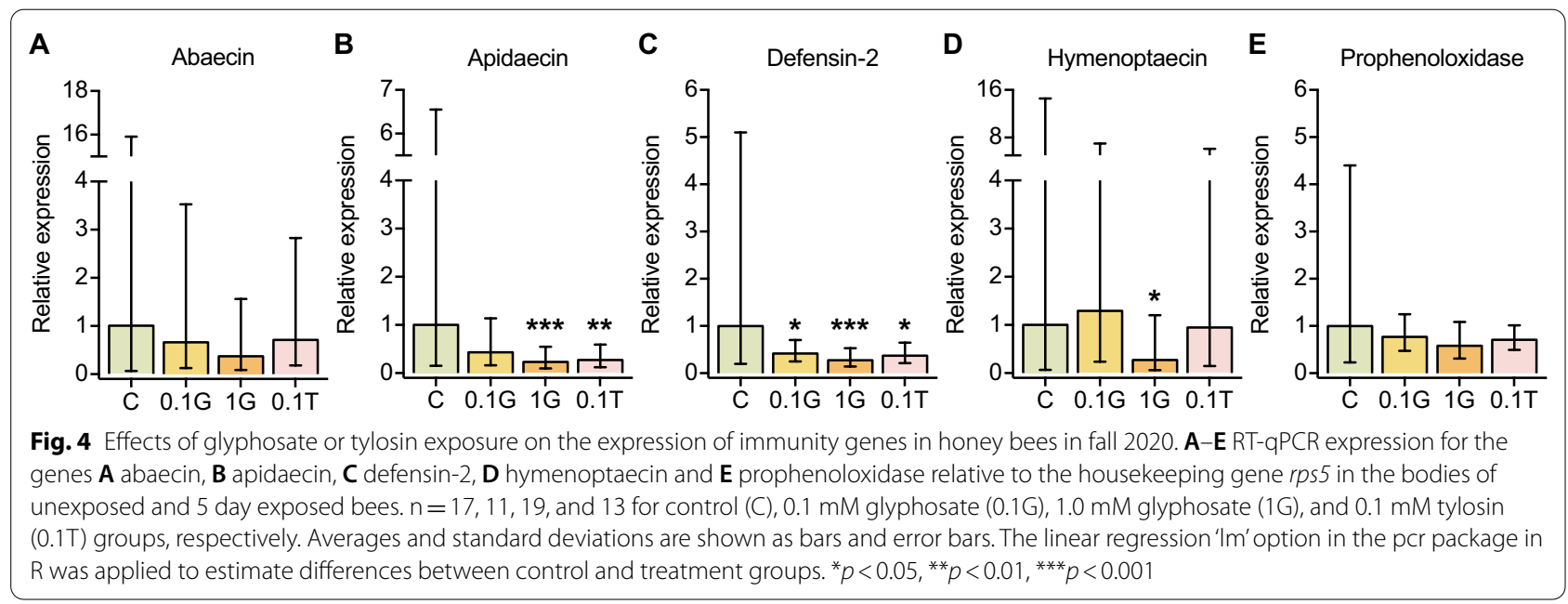

First, we performed ex vivo experiments to investigate whether glyphosate or tylosin inhibits the formation of an intermediate of the melanization pathway, dopachrome, as well as melanin in the hemolymph of honey bees at different stages of development and microbial acquisition: hemolymph was extracted from 1-day old bees, 


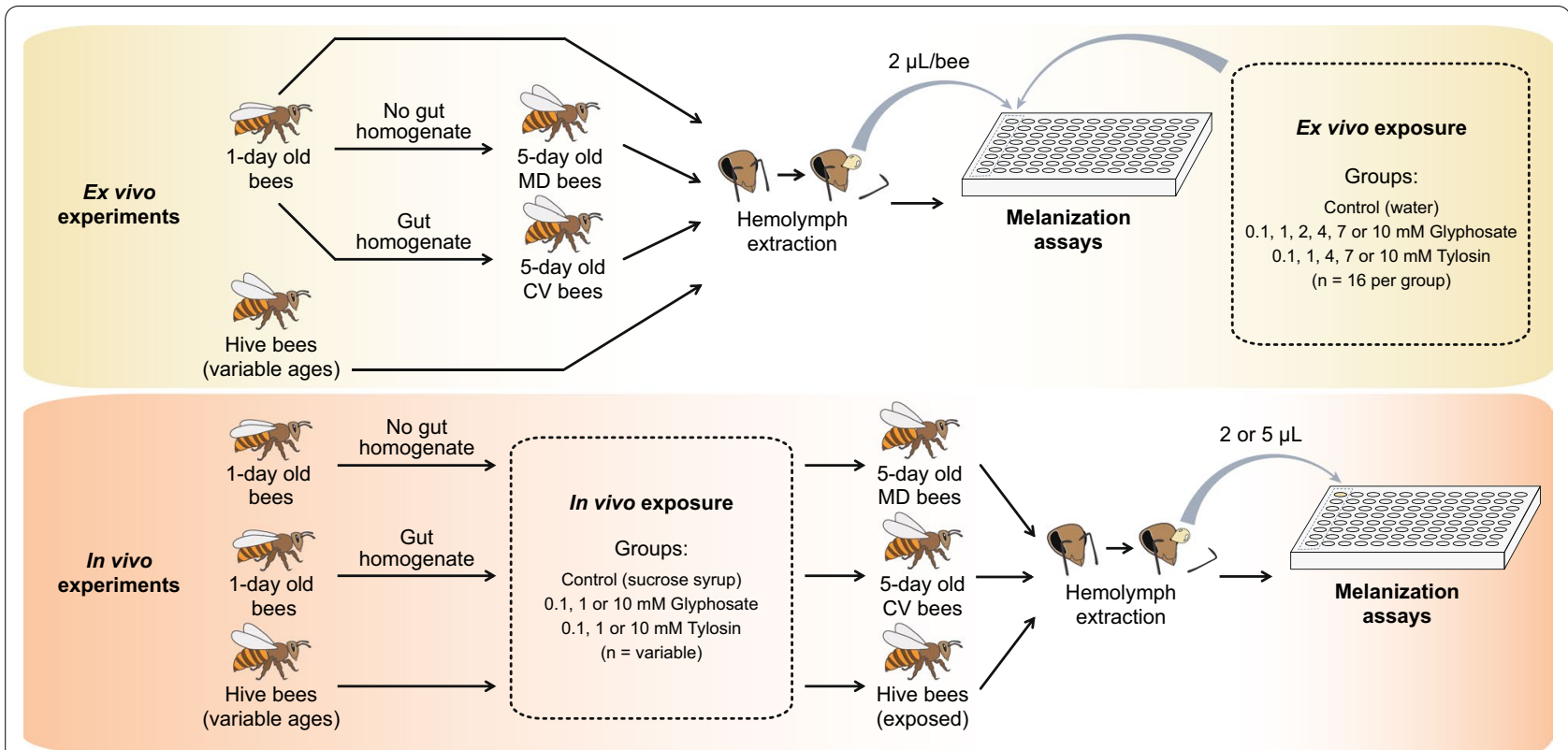

Fig. 5 Ex vivo and in vivo experiments to investigate the effects of glyphosate and tylosin on melanization in honey bees. Ex vivo experiments were performed with 1-day old bees, 5-day old bees lacking or containing a normal microbiota, and hive bees. $2 \mu \mathrm{L}$ of hemolymph were extracted from individual bees and used along with variable concentrations of glyphosate or tylosin (0, 0.1, 1, 2, 4, 7 or 10 mM) in melanization assays. In vivo experiments were performed with 5-day old bees lacking or containing a normal microbiota and hive bees previously exposed to different concentrations of glyphosate or tylosin $(0,0.1,1$ or $10 \mathrm{mM})$ for 5 days. $2 \mu \mathrm{L}$ or $5 \mu \mathrm{L}$ of hemolymph were extracted from exposed bees and used in melanization assays. $M D$ microbiota-defective, $C V$ conventional microbiota

5-day old bees lacking or containing a normal microbiota, and also worker bees collected from a hive that were not age-controlled. In all of these scenarios, concentrations of glyphosate higher than $2 \mathrm{mM}$ inhibited the production of dopachrome (Fig. 6) and melanin (Additional file 1: Fig. S4), while tylosin did not inhibit melanization in the honey bee hemolymph. Interestingly, dopachrome formation was also lower in $1 \mathrm{mM}$ glyphosate-exposed hemolymph of 1-day old bees than in unexposed hemolymph (Fig. 6A).

Unlike the ex vivo experiments, in which we extracted hemolymph from unexposed bees to perform the assays, we performed in vivo experiments, in which we first exposed honey bees to glyphosate or tylosin for 5 days (Additional file 1: Fig. S5), then extracted hemolymph and performed similar assays. This time, we tested whether the chemical could reach the hemolymph after ingestion and cause similar effects, since this represents a more realistic scenario. However, we did not find significant changes in dopachrome or melanin formation between unexposed and exposed bees (Fig. 7A, B), even when adding an exogenous substrate, L-DOPA, to increase the production of melanin and its intermediates (Fig. 7C-F). This was done for 5-day old bees lacking or containing a normal microbiota and older worker bees. The lack of an effect may be because glyphosate, once consumed by the bees, does not accumulate in the hemolymph, instead going to different compartments of the bee body or being taken up by the gut microbiota.

\section{Discussion}

\section{Glyphosate, similar to antibiotics, can downregulate the expression of AMPs}

One of the striking effects of glyphosate on honey bees is its impact on the gut microbiota, drastically reducing the abundance of beneficial bacterial symbionts, such as $S$. alvi. As shown in previous studies, S. alvi-monocolonized bees exhibit upregulation of genes encoding apidaecin in the guts [7], as well as abaecin and hymenoptaecin in the abdomens [8] when compared to microbiota-free bees; administration of heat-killed $S$. alvi cells also increases the expression of these AMPs, but in a less controlled way [8]. In our study, control bees were colonized with a normal microbiota and, therefore, were probably expressing basal levels of AMPs. Under these conditions, glyphosate exposure, besides killing S. alvi cells, promoted downregulation of the genes encoding apidaecin and defensin in whole bee body samples, as well as hymenoptaecin in both bee gut and whole bee body samples. These effects were observed in two out of three trials and, therefore, may vary according to tissue 

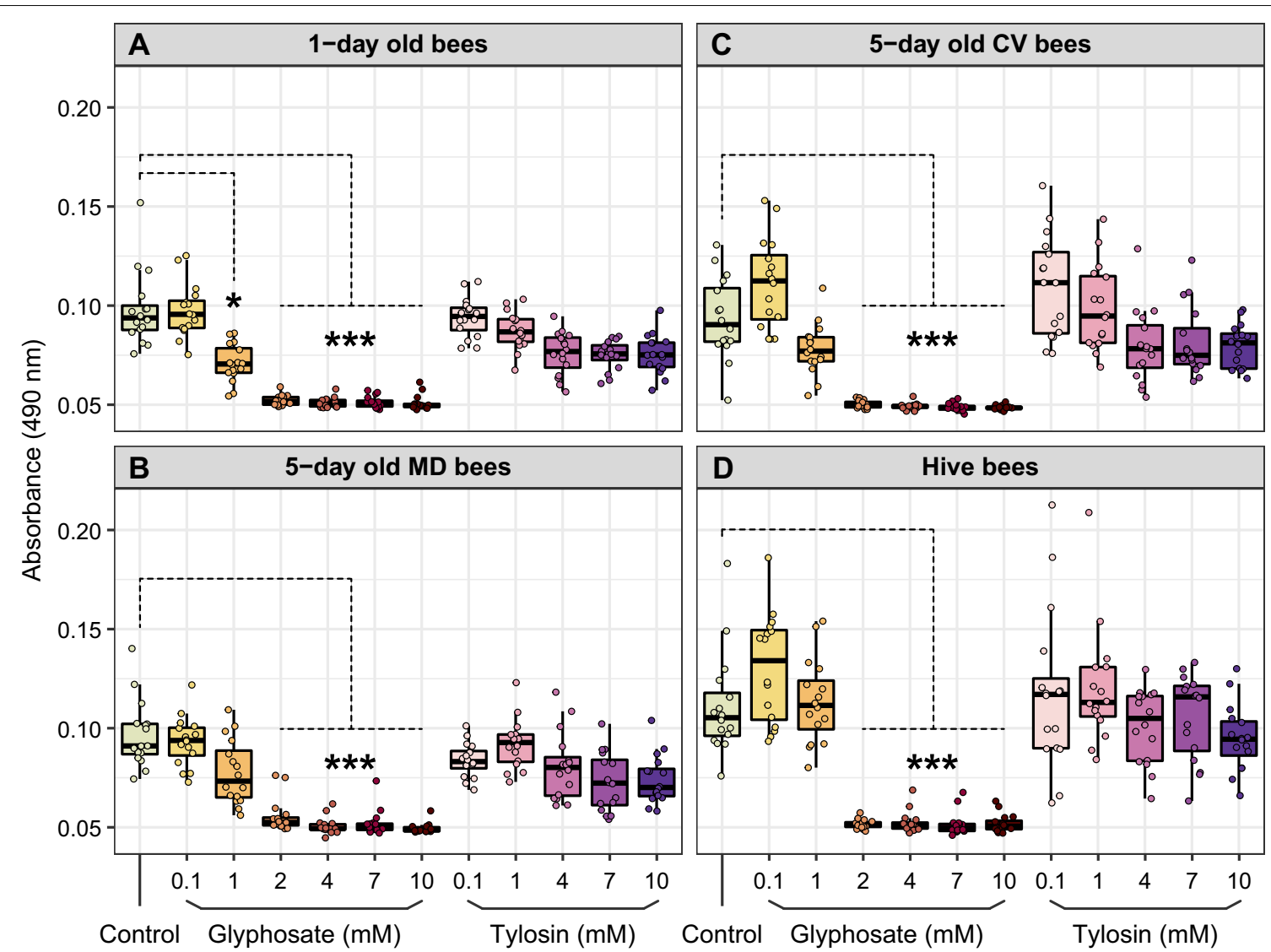

Fig. 6 Ex vivo experiments to investigate the effects of glyphosate or tylosin exposure on the melanization cascade in the hemolymph of honey bees. A-D The formation of dopachrome, an intermediate quinone of the melanization cascade, was measured after adding different concentrations of glyphosate or tylosin to the hemolymph extracted from $\mathbf{A}$ 1-day old bees, 5-day old bees $\mathbf{B}$ lacking or $\mathbf{C}$ containing a normal microbiota, and $\mathbf{D}$ hive bees. $n=16$ samples per group. Samples were incubated for 30 min at $30^{\circ} \mathrm{C}$, and absorbance was measured at $490 \mathrm{~nm}$. Significance between groups in each assay was measured with Kruskal-Wallis tests followed by Dunn's multiple-comparison tests. ${ }^{*} p<0.05$ and ${ }^{* * *} p<0.001$. MD microbiota defective, CV conventional microbiota

analyzed, experimental conditions or colony status, as suggested in other bee studies [32, 52].

Tylosin, an antibiotic commonly used in beekeeping, also affected the bee gut microbiota, as in previous studies [21, 22], and reduced the expression of apidaecin and defensin-2 in whole bee body samples, similar to glyphosate in this study and other antibiotics [19]. The effects of tylosin on the honey bee immune system is not a surprise, as previous studies have demonstrated negative effects of antibiotics on the bee immune system [19] and resistance to opportunistic pathogens [45]. In the transcriptome analysis of the fall 2018 experiment, several genes were expressed differently between tylosin-exposed and control groups $(p$-adj $<0.05)$, but mostly with fold-changes less than two; this was not observed in the summer 2020 experiment. Thus, the effects of these agrochemicals on expression of immunity genes may depend on colony status.
It remains to be elucidated whether the observed downregulation of AMPs is a direct effect of glyphosate or tylosin on the bee immune system or an indirect effect due to perturbations on the gut microbiota. AMP expression is typically modulated by exposure to specific opportunistic microbes, such as Gram negative and Gram positive bacteria, fungi, and microsporidia $[10,12,13,15$, 53, 54]. Some studies have also suggested that AMPs may be involved in the maintenance of microbiome homoeostasis [55]. In honey bees, the production of AMPs in the gut may play a dual role by inhibiting the proliferation of opportunistic microbes and by regulating the proliferation of the native bacteria. For example, while $S$. alvi strains appear to be tolerant of apidaecin, they are less tolerant of hymenoptaecin [7].

In insects, AMP expression is controlled by one of the two major immune response pathways, the immune deficiency pathway (Imd) or the Toll pathway [56]. Downregulation of genes encoding components of these pathways, 


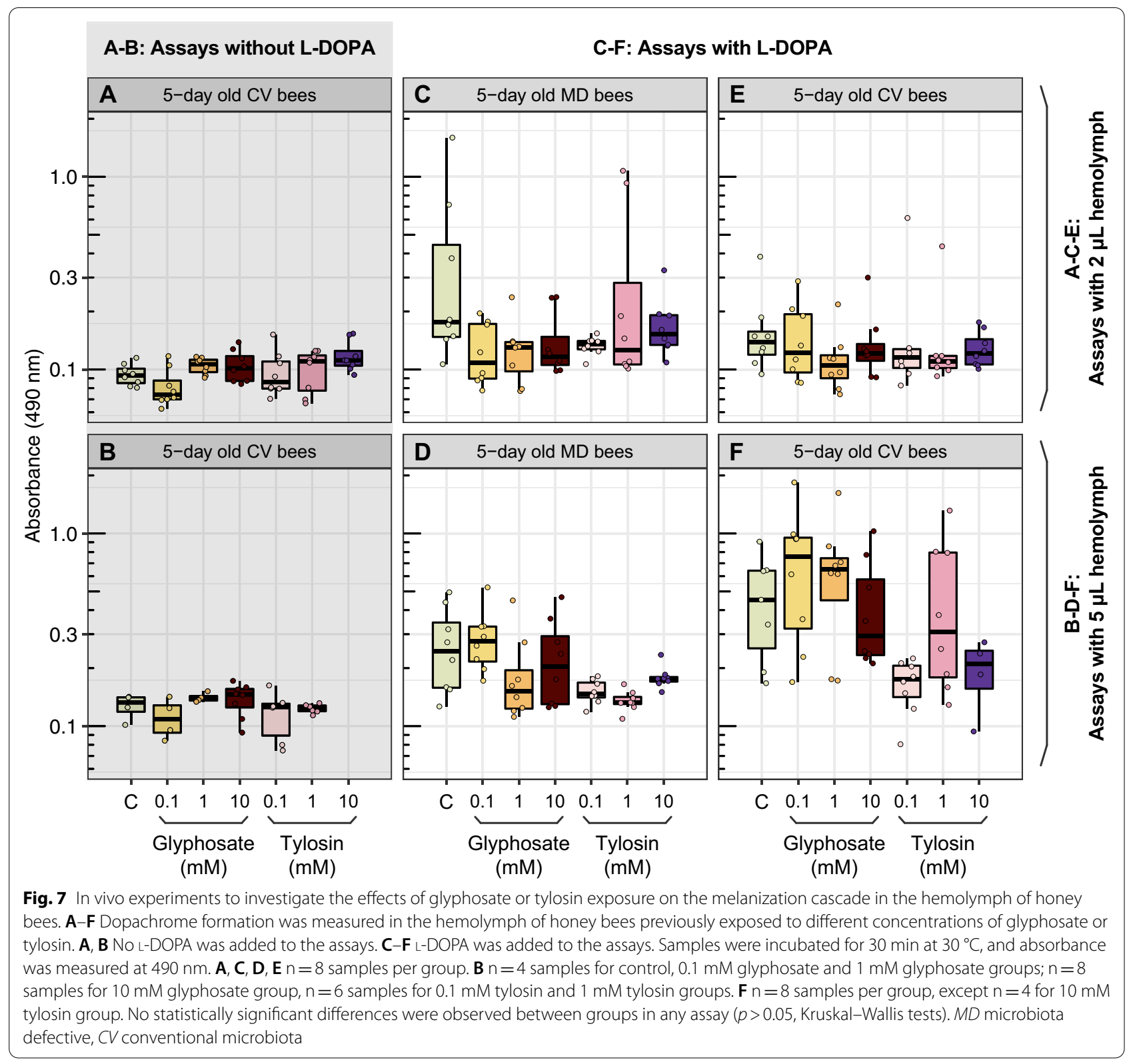

such as receptors, transcriptional factors, or AMPs may favor the proliferation of opportunistic microbes, which wouldn't grow otherwise [57]. In some instances, pathogens may find mechanisms to evade the host natural defenses; for example, S. marcescens, an opportunistic pathogen of worker bees, does not stimulate the host expression of AMPs [51] and is not susceptible to the AMPs apidaecin and hymenoptaecin, at least under in vitro conditions (Additional file 1: Fig. S3). Nonetheless, S. marcescens can take advantage of microbiome perturbations caused by exposure to anthropogenic chemicals, such as antibiotics and glyphosate, and cause disease $[18,21,23]$.
As caveats, in this study we primarily examined transcriptomic changes in guts and AMP expression in whole bee bodies of young worker bees, and therefore cannot assess effects of glyphosate or tylosin on expression of other genes in other specific tissues or in older worker bees, such as foragers. Other studies have shown differential expression of AMPs according to body part and age. For example, the AMP defensin is mainly expressed in the head and thorax of forager bees [58]. Also, the transcriptomes of foragers are affected by glyphosate-based formulations, but this exposure seems to increase rather than decrease apidaecin expression [38]. Moreover, other studies have 
demonstrated that honey bee larvae exposed to glyphosate exhibit variable transcriptional changes [32, 52].

\section{Does glyphosate or tylosin inhibit melanization in honey bees?}

Another major component of the immune system in insects and many other invertebrates is the melanization of pathogens and injured tissues [59]. The melanization process involves a series of redox reactions, typically mediated by phenoloxidases, which once activated upon wound or infection, oxidize phenols in the hemolymph into toxic quinones, which polymerize nonenzymatically and form melanin [60]. Then, melanin and its highly reactive and toxic precursors surround and expose the invader to reactive oxygen species culminating in its death [61].

Previous studies have demonstrated that glyphosate inhibits melanin production in the fungus Cryptococcus neoformans [42] and in the hemolymph of the insects Galleria mellonella and Anopheles gambiae [43]. Glyphosate does not directly inhibit phenoloxidases, but instead affects the melanization cascade by acting as a synergistic antioxidant and disrupting the redox reactions required for melanization, which halts the production of melanin [43]. In this study, we saw that concentrations of glyphosate higher than $2 \mathrm{mM}$ inhibit melanization in the hemolymph of honey bees in ex vivo studies, but we were unable to recapitulate these findings in in vivo studies. Once bees are exposed to glyphosate, this herbicide may pass through the hemolymph to reach different compartments of the bee body, but may not accumulate in the hemolymph. Based on previous studies on glyphosate-induced perturbations of the bee gut microbiota, it is expected that a portion of the ingested glyphosate is not absorbed, passes intact into the hindgut, and reaches high enough concentrations to perturb the microbiota at least in the ileum, the proximal compartment of the hindgut, where $S$. alvi resides. S. alvi abundance is drastically reduced upon glyphosate exposure, based on results of several studies [21-24].

Interestingly, F. perrara, another gut symbiont commonly found in honey bees, upregulates the expression of genes associated with the melanization cascade-as well as AMP production-forming a scab in the pylorus, region connecting the midgut to the ileum [9]. However, glyphosate seems not to affect $F$. perrara abundance in the bee gut, although this bacterium encodes the susceptible version of the enzyme that glyphosate inhibits [21]. It is unclear whether melanization inhibition could affect $F$. perrara colonization patterns in the bee gut, with potential consequences for host health.

Unlike glyphosate, tylosin exposure does not affect melanization in the bee hemolymph, at least under the tested conditions. Tetracycline, another antibiotic commonly used in beekeeping [46], does not affect melanin content or tyrosinase activity in human melanocytes [62], suggesting that the same may occur in bee hemocytes. However, the lack of effects on melanization does not hold true for all antibiotics, as demonstrated for fluoroquinolone antibiotics, such as ciprofloxacin, norfloxacin and moxifloxacin, which decrease melanin content and tyrosinase activity in human melanocytes [63, 64].

In summary, our results show that glyphosate, unlike tylosin, can inhibit melanization in the bee hemolymph, but this would only happen in vivo if bees are exposed to high levels, such that the herbicide reaches concentrations of at least $2 \mathrm{mM}$ in the hemolymph. This could happen, for example, if forager bees are directly exposed to herbicide formulations when foraging.

\section{Conclusions}

This study provides experimental evidence that glyphosate exposure, similar to antibiotics such as tylosin, not only can cause dysbiosis in the honey bee Apis mellifera, as shown previously [21-24], but also can alter immune response pathways, by downregulating the expression of host-produced AMPs. We also observed that glyphosate can potentially affect melanization in the bee hemolymph, depending on level of exposure and delivery to the hemolymph. Since AMP production and melanization are two major components of the innate immune system of honey bees, disruption of these pathways may promote negative consequences to host health, such as increased susceptibility to infection and reduced lifespan.

\section{Methods}

In vivo experiments for transcriptome studies

To investigate the effects of glyphosate exposure on the expression of AMPs and other immunity-related genes in gut tissues or in whole bee bodies, we performed three in vivo experiments with newly emerged honey bees (Apis mellifera) originating from different hives kept at the University of Texas at Austin (UT-Austin). As we describe below, these experiments were performed in different seasons (fall 2018, summer 2020 and fall 2020), and the experimental conditions slightly varied based on the findings we obtained in past experiments (Fig. 1).

In the fall 2018 experiment, late-stage pupae (with eyes pigmented but lacking movement) were extracted from a brood frame, transferred to clean plastic bins and placed in an incubator at $35{ }^{\circ} \mathrm{C}$ and $\sim 60 \%$ relative humidity to simulate hive conditions until emerging as adults. Healthy newly emerged workers (NEWs) were transferred to cup cages containing sterile sucrose syrup and bee bread mixed with a gut homogenate so they could acquire their native microbiota [22]. Cup cages 
were divided into a control group, which was fed sterile sucrose syrup, and three treatment groups, which were fed $0.1 \mathrm{mM}$ glyphosate in sterile sucrose syrup, $1 \mathrm{mM}$ glyphosate in sterile sucrose syrup or $0.1 \mathrm{mM}$ tylosin in sterile sucrose syrup, respectively, for 5 days. The glyphosate concentrations were chosen to be in the range detected in nectar and pollen of recently sprayed plants in a semi-field experiment [65]. Tylosin is an antibiotic commonly used in beekeeping and served in this study as a comparison treatment, expected to have a major effect, as antibiotics including tylosin are known to disrupt the gut microbiota of honey bees $[44,45]$ and to affect the expression of immunity-related genes [19]. The tylosin concentration used is far below that recommended for hive applications.

Each group consisted of 4 cup cages, with $26-30$ bees per cup cage. In the end of the treatment, 15 bees were sampled from each group, placed in $5 \mathrm{~mL}$ Falcon tubes, and stored at $-80{ }^{\circ} \mathrm{C}$ until further analyses. As described below, RNA was extracted from individual bee guts and pooled for 3'-Tag RNA sequencing (3 RNA samples per pooled sample, 5 pooled samples per group) or checked individually for RT-qPCR analysis (15 RNA samples per group). Samples from this experiment were produced as part of a recently published study in which we investigated the effects of glyphosate on the honey bee gut microbiota [22].

The summer 2020 experiment was performed to replicate the fall 2018 experiment with some altered conditions. In 2020, pupae were allowed to emerge naturally from a brood frame kept in an incubator at $35{ }^{\circ} \mathrm{C}$ and $\sim 60 \%$ relative humidity. This method enables a more natural emergence process, wherein bees are exposed to environmental microbes present on the frame before the experimental exposure to the native microbiota in gut homogenates. In the hive, bees would also be exposed to environmental microbes and would acquire their native microbiota by interaction with nurse bees or fecal material. One-day-old bees were transferred to cup cages and treated as described for the fall 2018 experiment.

The fall 2020 experiment was performed similarly to the fall 2018 experiment, but with bees from a different hive. This time, RNA was extracted from whole bee bodies to extend the findings from bee guts to other bee body compartments.

\section{Dissections and RNA extractions}

For the fall 2018 and summer 2020 experiments, bee guts were dissected with flame-sterilized forceps under aseptic conditions and on ice, and RNA was extracted from individual guts using the Quick-RNA ${ }^{\mathrm{TM}}$ Miniprep kit (Zymo Research ${ }^{\circledR}$ ). For the fall 2020 experiment, total RNA was extracted from whole bee bodies. Guts (fall
2018, summer 2020) or whole bee bodies (fall 2020) were crushed in $100 \mu \mathrm{L}$ of RNA Lysis Buffer, resuspended in a total of $600 \mu \mathrm{L}$ of the same solution, and transferred to a capped vial containing $\sim 0.5 \mathrm{~mL}$ of $0.1-\mathrm{mm}$ Zirconia beads (BioSpec Products Inc.). Samples were bead-beaten for $2 \times 30 \mathrm{~s}$, centrifuged at $14,000 \mathrm{rpm}$ for $30 \mathrm{~s}$, and transferred to a new microtube. After this step, extraction followed the protocol provided by Zymo Research ${ }^{\circledR}$. Final RNA samples were eluted in $50 \mu \mathrm{L}$ of water and stored at $-80^{\circ} \mathrm{C}$.

\section{Library preparation for 3'-Tag RNA sequencing}

Aliquots of RNA samples from the fall 2018 and summer 2020 experiments were initially pooled according to cup cage source (1000 $\eta$ g of each RNA sample), giving a final number of 40 pooled RNA samples, 20 samples per experiment, 5 samples per group, 3 bees per sample. Then, pooled samples were diluted to a final RNA concentration of $100 \mathrm{\eta g} / \mathrm{mL}$ and submitted for $3^{\prime}$-Tag RNA sequencing (Admera Health Inc.). QuantSeq $3^{\prime}$ mRNA-Seq Library Prep Kit FWD for Illumina (Lexogen Inc.) was used to create libraries for $1 \times 50 \mathrm{bp}$ single-end sequencing on an Illumina HiSeq $\mathrm{X}$ instrument (Genohub project \# 3979681), which generated a total of $473,838,012$ reads, ranging from $9,772,385$ to $13,966,825$ reads per library.

\section{Processing of $3^{\prime}$-Tag RNA sequencing data}

$3^{\prime}$-Tag RNA-seq data were processed following the scripts provided by Lexogen Inc. at https://www.lexog en.com/quantseq-data-analysis. Sequence visualization and quality control were performed with FastQC [66]. Adapter contamination, polyA tail read through, and low quality tails were trimmed using the bbduk.sh script in the BBMap package [67]. Then, the STAR aligner [68] was used to build a STAR index using the most updated versions of the Apis mellifera genome (GCF_003254395.2 Amel_HAv3.1_genomic.fna) and gene annotations (GCF_003254395.2_Amel_HAv3.1_genomic.gtf), and used to align and map the reads to the Apis mellifera genome, generating gene counts files which were used in downstream analyses. Differential gene expression analysis was performed using DESeq2 [69] in R version 3.5.2 [70]. Gene counts were normalized, and low counts were filtered whenever there were less than 5 samples with normalized counts greater than or equal to 5 , giving a final number of 9833 genes. The comparisons of gene expression were made between the control and each treatment in each experiment, and a gene was considered significant if the false discovery rate (FDR) was less than 0.05 and the absolute fold change more than 2 . 


\section{Gene relative expression analyses}

We performed RT-qPCR analyses to confirm the findings observed in the $3^{\prime}$-Tag RNA sequencing data for the fall 2018 experiment, and to investigate potential changes in the expression of specific immunity-related genes in the fall 2020 experiment. For this, cDNA was synthesized from $800 \eta \mathrm{g}$ of each individual RNA sample from each of these two experiments using the qScript cDNA Synthesis Kit (QuantaBio, USA). cDNA samples (120 in total) were ten-fold diluted to be used as template for RTqPCR analyses. The fold-change in expression between control and treated bees were determined for the genes encoding hymenoptaecin and Toll-like receptor 4 for the fall 2018 experiment, and abaecin, apidaecin, defensin, hymenoptaecin and prophenoloxidase for the fall 2020 experiment. For these measures, $10 \mu \mathrm{L}$ reactions were carried out on 384-well plates on a Thermo Fisher ViiA7 instrument using $5 \mu \mathrm{L}$ of iTaq Universal SYBR Green Supermix (Bio-Rad Inc.), $0.05 \mu \mathrm{L}$ of each forward and reverse $100 \mu \mathrm{M}$ primer (Additional file 1: Table S1), 3.9 $\mu \mathrm{L}$ of $\mathrm{H}_{2} \mathrm{O}$, and $1.0 \mu \mathrm{L}$ of template cDNA. The cycling conditions consisted of an initial cycle of $50{ }^{\circ} \mathrm{C}$ for $2 \mathrm{~min}$ and $95^{\circ} \mathrm{C}$ for $2 \mathrm{~min}$, followed by 40 cycles of a two-step PCR of $95{ }^{\circ} \mathrm{C}$ for $15 \mathrm{~s}$ and $60{ }^{\circ} \mathrm{C}$ for $1 \mathrm{~min}$. Expression levels were measured in triplicate for each biological replicate and normalized against the housekeeping gene rps5 (Additional file 1: Table S1) [71]. Relative expression was performed by means of the $\Delta \Delta C_{\mathrm{T}}$ method, and differences in expression between control and treatment groups were investigated using the linear regression ' $1 \mathrm{~m}$ ' test in the pcr package [72] in $\mathrm{R}$ version 3.5.2 [70]. $p$ values lower than 0.05 were considered statistically significant. No RT-qPCR analyses were performed for RNA samples from the summer 2020 experiment since we did not observe any significant changes in the $3^{\prime}$-Tag RNA sequencing data.

\section{Microbial abundance and composition analyses}

For the fall 2018 and summer 2020 experiments, cDNA was synthesized from $2 \mu \mathrm{L}$ of each normalized RNA sample that was also used for the $3^{\prime}$-Tag RNA-seq library preparation. cDNA samples (40 in total) were ten-fold diluted to be used as templates for 16S rRNA library preparation and qPCR analyses.

16S rRNA library preparation consisted of two PCR reactions performed as described in [22]. Briefly, PCR 1 amplified the V4 region of the 16S rRNA gene and was performed in $20 \mu \mathrm{L}$ triplicate reactions containing $0.5 \mu \mathrm{L}$ of forward $(8 \mu \mathrm{M} 515 \mathrm{~F})$ and reverse $(8 \mu \mathrm{M} 806 \mathrm{R})$ primers (Additional file 1: Table S1), $8 \mu \mathrm{L}$ of $2.5 \times 5$ PRIME HotMasterMix (Quantabio, USA) and $1 \mu \mathrm{L}$ of template cDNA. Cycling conditions consisted of $94{ }^{\circ} \mathrm{C}$ for $3 \mathrm{~min}$; 30 cycles of $94{ }^{\circ} \mathrm{C}$ for $45 \mathrm{~s}, 50{ }^{\circ} \mathrm{C}$ for $60 \mathrm{~s}, 72{ }^{\circ} \mathrm{C}$ for $90 \mathrm{~s}$, then $72{ }^{\circ} \mathrm{C}$ for $10 \mathrm{~min}$. PCR 2 attached dual indices and Illumina sequencing adapter to the products of PCR 1 and consisted of $25 \mu \mathrm{L}$ single reactions containing a unique combination of $2 \mu \mathrm{L}$ of $5 \mu \mathrm{M}$ index primers (see Additional file 1: Table S1), $10 \mu \mathrm{L}$ of $2.5 \times 5$ PRIME HotMasterMix (Quantabio, USA) and $5 \mu \mathrm{L}$ of PCR 1 product. Cycling conditions consisted of $94{ }^{\circ} \mathrm{C}$ for $3 \mathrm{~min} ; 10$ cycles of $94{ }^{\circ} \mathrm{C}$ for $20 \mathrm{~s}, 55^{\circ} \mathrm{C}$ for $15 \mathrm{~s}, 72{ }^{\circ} \mathrm{C}$ for $60 \mathrm{~s}$; then $72{ }^{\circ} \mathrm{C}$ for $10 \mathrm{~min}$. For both PCR reactions, products were purified with $0.8 \times$ HighPrep $^{\text {TM }}$ PCR magnetic beads (MagBio, USA) and quantified fluorometrically (Qubit, Thermo

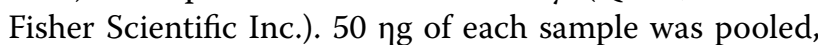
and the resulting library was diluted to a final concentration of $50 \mathrm{pM}$. The diluted library was loaded onto an Illumina iSeq cartridge according to the manufacturer's instructions and subjected to Illumina sequencing on the iSeq platform $(2 \times 150$ sequencing run, instrument model number: FS10000184). 5\% PhiX was used to increase library diversity.

Illumina sequence reads were demultiplexed according to their barcode sequences by the iSeq software and processed in QIIME 2 version 2019.10 [73]. Downstream analyses were performed with forward reads, because of insufficient overlap between forward and reverse reads. Primer sequences were removed using the cutadapt plugin [74] and the reads were truncated to length of $120 \mathrm{bp}$. Trimmed reads were filtered and denoised, and chimeric reads were removed using the DADA2 plugin [75]. Taxonomy was assigned to amplicon sequence variants (ASVs) using the SILVA database in the feature-classifier plugin [76]. Reads with lower than $0.1 \%$ abundance were removed using the feature-table plugin, as well as unassigned, mitochondrial, and chloroplast reads using the taxa filter-table plugin.

qPCR analyses were performed as described in the previous section using universal bacterial $16 \mathrm{~S}$ rRNA gene primers (Additional file 1: Table S1). Total bacterial $16 \mathrm{~S}$ rRNA gene transcripts were estimated by standard curves from amplification of the cloned target sequence in a pGEM-T vector (Promega). For specific bacterial species, 16S rRNA gene transcripts were estimated by multiplying the percent relative abundance of each species (obtained by $16 \mathrm{~S}$ rRNA amplicon sequencing) by the total bacterial $16 \mathrm{~S}$ rRNA gene transcripts (obtained by qPCR).

\section{Minimum inhibitory concentration assays}

Four strains of Serratia marcescens (Db11, Ss1, kz11 and kz19) were cultivated in the presence of different concentrations of the AMPs apidaecin 1a, apidaecin 1b and hymenoptaecin (synthesized by NovoPro Bioscience Inc.) to determine the minimum inhibitory concentration (MIC). Escherichia coli strain K12 and S. alvi strain wkB2 
were tested for comparisons. Assays were performed as described in [7]. Briefly, solutions of $100 \mu \mathrm{g} / \mathrm{mL}$ of each AMP were serially diluted two-fold in $50 \%$ brain heart infusion broth (BHI) in 96-well plates, leaving a volume of $100 \mu \mathrm{L}$ in each well. Bacterial strains were cultured on heart infusion agar with $5 \%$ sheep blood at $35{ }^{\circ} \mathrm{C}$ and $5 \%$ $\mathrm{CO}_{2}$. Colonies from overnight cultures were first diluted in $50 \%$ BHI to obtain an optical density (OD) of 0.5 at $600 \mathrm{~nm}$, then 100-fold diluted in 50\% BHI. Finally, 100 $\mu \mathrm{L}$ of diluted cultures were transferred to the wells. Final concentrations of AMPs in the wells ranged from 0.78 to $50 \mu \mathrm{g} / \mathrm{mL}$. Plates were incubated at $35{ }^{\circ} \mathrm{C}$ and $5 \% \mathrm{CO}_{2}$ and OD was measured at $600 \mathrm{~nm}$ every $24 \mathrm{~h}$ for $48 \mathrm{~h}$. MIC was defined as the lowest concentration of AMP that inhibited growth of bacteria compared to controls.

\section{Ex vivo and in vivo experiments for melanization assays}

During winter 2020, we performed ex vivo and in vivo experiments with honey bee hemolymph and honey bees, respectively, to examine the effects of glyphosate on melanization, which is a key part of the immune response. For the ex vivo experiments, a brood frame and hive bees (not age-controlled) were collected from a hive on the UT-Austin campus and transferred to an incubator. The next day, $2 \mu \mathrm{L}$ of hemolymph were extracted from newlyemerged bees and worker bees as described in [77], transferred to 96 -well plates on ice, then preserved at $-80^{\circ} \mathrm{C}$. Other newly emerged bees were transferred to cup cages and split into two groups, which were provided sterile sucrose syrup and bee bread. Only one of these groups was allowed to acquire a normal microbiota by adding to the bee bread a gut homogenate suspension, as described in [22]. Then, $2 \mu \mathrm{L}$ of hemolymph were also extracted from 5-day old microbiota-defective bees and 5-day old bees with a conventional microbiota. These bees were not exposed to glyphosate or tylosin. For the melanization assays, plates were thawed on ice, added $140 \mu \mathrm{L}$ of distilled water, $20 \mu \mathrm{L}$ of a phosphate-buffered saline (PBS) solution ( $\left.150 \mathrm{mM} \mathrm{NaCl}, 10 \mathrm{mM} \mathrm{Na}_{2} \mathrm{HPO}_{4}, \mathrm{pH} 6.5\right)$ and $18 \mu \mathrm{L}$ of glyphosate or tylosin solution to give a final concentration in the range of 0.1 to $10 \mathrm{mM}$. For measurements of dopachrome formation, an intermediate of the melanization pathway, plates were incubated at $30^{\circ} \mathrm{C}$ for $30 \mathrm{~min}$ and absorbances were measured at $490 \mathrm{~nm}$. After that, plates were incubated at room temperature for 5 days after which absorbances were measured at $490 \mathrm{~nm}$ again to determine melanin production.

For the in vivo experiments, newly emerged bees and hive bees (not age-controlled) were treated with different concentrations of glyphosate or tylosin $(0.1,1$ or $10 \mathrm{mM}$ ) for 5 days. Before the beginning of the chemical treatment, newly emerged bees were split into two main groups, in which only one was allowed to acquire the normal microbiota by providing gut homogenates to the bee bread, as described in [22]. Then, $2 \mu \mathrm{L}$ of hemolymph were extracted from control and treatment bees, transferred to 96-well plates on ice, and frozen at $-80^{\circ} \mathrm{C}$. For the melanization assays, only $140 \mu \mathrm{L}$ of distilled water and $20 \mu \mathrm{L}$ of a PBS solution $(150 \mathrm{mM}$ $\mathrm{NaCl}, 10 \mathrm{mM} \mathrm{Na}{ }_{2} \mathrm{HPO}_{4}, \mathrm{pH}$ 6.5) were added to the plates. No chemical solution was added this time, since bees were previously exposed to glyphosate or tylosin. In some plates, $20 \mu \mathrm{L}$ of a $6 \mathrm{mg} / \mathrm{mL}$ L-DOPA solution was added to speed up the melanization reaction. Plates were incubated at $30{ }^{\circ} \mathrm{C}$ for $30 \mathrm{~min}$ and absorbances were measured at $490 \mathrm{~nm}$. To confirm the results from the second set of in vivo melanization experiments, we repeated the assays with $5 \mu \mathrm{L}$ of hemolymph, as we considered that a higher concentration of hemolymph could favor the melanization reaction.

\section{Chemicals and solutions}

Glyphosate standard was purchased from Research Products International, USA (Lot: 32612-38399). Tylosin tartrate was purchased from GoldBio, USA (Lot: 2313.081915A). 3-(3,4-Dihydroxyphenyl)-L-alanine (L-DOPA) was purchased from TCI Chemicals, USA (Lot: UF6JK-JD). For in vitro experiments, glyphosate, tylosin and L-DOPA were dissolved in distilled water. For in vivo experiments, glyphosate and tylosin were initially dissolved in distilled water, then diluted to the final concentration with filter-sterilized 0.5 M sucrose syrup.

\section{Abbreviations \\ AMP: Antimicrobial peptide; BHI: Brain heart infusion; cDNA: Complemen- tary deoxyribonucleic acid; L-DOPA: 3-(3,4-Dihydroxyphenyl)-L-alanine; MIC: Minimum inhibitory concentration; NCBI: National Center for Biotechnology Information; OD: Optical density; PBS: Phosphate-buffered saline; RNA: Ribo- nucleic acid; rRNA: Ribosomal RNA; RT-qPCR: Reverse transcription quantita- tive polymerase chain reaction.}

\section{Supplementary Information}

The online version contains supplementary material available at https://doi. org/10.1186/s42523-022-00165-0.

Additional file 1. Supplementary figures and tables.

Additional file 2. Supplementary dataset.

\section{Acknowledgements}

Thanks to Kim Hammond for maintaining the honey bee hives and making a nice bee image for Figures 1 and 5 .

\section{Authors' contributions}

EVSM and NAM designed the study. EVSM and JEP performed the experiments. EVSM performed data analysis and drafted the manuscript. JEP 
and NAM revised the manuscript. All authors read and approved the final manuscript.

\section{Funding}

This work was supported by the USDA National Institute of Food and Agriculture (Grant Number 2018-67013-27540).

\section{Availability of data and materials}

Sequencing data are available on NCBI BioProject PRJNA703064. Other data are included in this published article and its Additional information files (Additional file 1 and Additional file 2).

\section{Declarations}

\section{Ethics approval and consent to participate}

Not applicable.

\section{Consent for publication}

Not applicable.

\section{Competing interests}

The authors declare that they have no competing interests.

Received: 11 March 2021 Accepted: 4 February 2022

Published online: 22 February 2022

\section{References}

1. Zheng D, Liwinski T, Elinav E. Interaction between microbiota and immunity in health and disease. Cell Res. 2020;30:492-506.

2. Wu H-J, Wu E. The role of gut microbiota in immune homeostasis and autoimmunity. Gut Microbes. 2012;3:4-14.

3. Kwong WK, Moran NA. Gut microbial communities of social bees. Nat Rev Microbiol. 2016;14:374-84.

4. Zheng H, Powell JE, Steele MI, Dietrich C, Moran NA. Honeybee gut microbiota promotes host weight gain via bacterial metabolism and hormonal signaling. PNAS. 2017;114:4775-80.

5. Zheng H, Steele MI, Leonard SP, Motta EVS, Moran NA. Honey bees as models for gut microbiota research. Lab Anim. 2018;47:317-25.

6. Martinson VG, Moy J, Moran NA. Establishment of characteristic gut bacteria during development of the honeybee worker. Appl Environ Microbiol. 2012;78:2830-40.

7. Kwong WK, Mancenido AL, Moran NA. Immune system stimulation by the native gut microbiota of honey bees. R Soc Open Sci. 2017:4:170003.

8. Horak RD, Leonard SP, Moran NA. Symbionts shape host innate immunity in honeybees. Proc R Soc B R Soc. 2020;287:20201184.

9. Emery O, Schmidt K, Engel P. Immune system stimulation by the gut symbiont Frischella perrara in the honey bee (Apis mellifera). Mol Ecol. 2017:26:2576-90.

10. Antúnez K, Martín-Hernández R, Prieto L, Meana A, Zunino P, Higes M. Immune suppression in the honey bee (Apis mellifera) following infection by Nosema ceranae (Microsporidia). Environ Microbiol. 2009;11:2284-90.

11. Evans JD, Aronstein K, Chen YP, Hetru C, Imler J-L, Jiang H, et al. Immune pathways and defence mechanisms in honey bees Apis mellifera. Insect Mol Biol. 2006;15:645-56.

12. Casteels P, Ampe C, Riviere L, van Damme J, Elicone C, Fleming M, et al. Isolation and characterization of abaecin, a major antibacterial response peptide in the honeybee (Apis mellifera). Eur J Biochem. 1990;187:381-6.

13. Casteels $P$, Ampe $C$, Jacobs F, Vaeck M, Tempst P. Apidaecins: antibacterial peptides from honeybees. EMBO J. 1989;8:2387-91.

14. Klaudiny J, Albert Š, Bachanová K, Kopernický J, Šimúth J. Two structurally different defensin genes, one of them encoding a novel defensin isoform, are expressed in honeybee Apis mellifera. Insect Biochem Mol Biol. 2005;35:11-22.

15. Casteels $P$, Ampe $C$, Jacobs F, Tempst P. Functional and chemical characterization of Hymenoptaecin, an antibacterial polypeptide that is infection-inducible in the honeybee (Apis mellifera). J Biol Chem. 1993;268:7044-54.
16. Sheehan G, Garvey A, Croke M, Kavanagh K. Innate humoral immune defences in mammals and insects: the same, with differences? Virulence. 2018:9:1625-39.

17. Marmaras VJ, Charalambidis ND, Zervas CG. Immune response in insects: the role of phenoloxidase in defense reactions in relation to melanization and sclerotization. Arch Insect Biochem Physiol. 1996;31:119-33.

18. Raymann K, Shaffer Z, Moran NA. Antibiotic exposure perturbs the gut microbiota and elevates mortality in honeybees. PLoS Biol. 2017; 15:e2001861.

19. Li JH, Evans JD, Li WF, Zhao YZ, DeGrandi-Hoffman G, Huang SK, et al. New evidence showing that the destruction of gut bacteria by antibiotic treatment could increase the honey bee's vulnerability to Nosema infection. PLoS ONE. 2017;12:e0187505.

20. Dai P, Yan Z, Ma S, Yang Y, Wang Q, Hou C, et al. The herbicide glyphosate negatively affects midgut bacterial communities and survival of honey bee during larvae reared in vitro. J Agric Food Chem. 2018;66:7786-93.

21. Motta EVS, Raymann K, Moran NA. Glyphosate perturbs the gut microbiota of honey bees. PNAS. 2018;115:10305-10.

22. Motta EVS, Moran NA. Impact of glyphosate on the honey bee gut microbiota: effects of intensity, duration, and timing of exposure. mSystems. 2020;5:e00268-e320.

23. Motta EVS, Mak M, De Jong TK, Powell JE, O'Donnell A, Suhr KJ, et al. Oral or topical exposure to glyphosate in herbicide formulation impacts the gut microbiota and survival rates of honey bees. Appl Environ Microbiol. 2020 [cited 2020 Sep 16];86. Available from https://aem.asm.org/content/ 86/18/e01150-20.

24. Blot N, Veillat L, Rouzé R, Delatte H. Glyphosate, but not its metabolite AMPA, alters the honeybee gut microbiota. PLOS ONE. 2019;14:e0215466.

25. Dechartress J, Pawluski JL, Gueguen M-M, Jablaoui A, Maguin E, Rhimi M, et al. Glyphosate and glyphosate-based herbicide exposure during the peripartum period affects maternal brain plasticity, maternal behavior and microbiome. J Neuroendocrinol. 2019;31:e12731.

26. Aitbali Y, Ba-M'hamed S, Elhidar N, Nafis A, Soraa N, Bennis M. Glyphosate based-herbicide exposure affects gut microbiota, anxiety and depression-like behaviors in mice. Neurotoxicol Teratol. 2018;67:44-9.

27. Lozano VL, Defarge N, Rocque L-M, Mesnage R, Hennequin D, Cassier $R$, et al. Sex-dependent impact of Roundup on the rat gut microbiome. Toxicol Rep. 2018;5:96-107.

28. Suppa A, Kvist J, Li X, Dhandapani V, Almulla H, Tian AY, et al. Roundup causes embryonic development failure and alters metabolic pathways and gut microbiota functionality in non-target species. Microbiome. 2020:8:170.

29. Ruuskanen S, Rainio MJ, Gómez-Gallego C, Selenius O, Salminen S, Collado MC, et al. Glyphosate-based herbicides influence antioxidants, reproductive hormones and gut microbiome but not reproduction: a longterm experiment in an avian model. Environ Pollut. 2020;266:115108.

30. Newman MM, Hoilett N, Lorenz N, Dick RP, Liles MR, Ramsier C, et al. Glyphosate effects on soil rhizosphere-associated bacterial communities. Sci Total Environ. 2016:543:155-60.

31. Van Bruggen AHC, He MM, Shin K, Mai V, Jeong KC, Finckh MR, et al. Environmental and health effects of the herbicide glyphosate. Sci Total Environ. 2018;616-617:255-68.

32. Vázquez DE, Ilina N, Pagano EA, Zavala JA, Farina WM. Glyphosate affects the larval development of honey bees depending on the susceptibility of colonies. PLOS ONE. 2018;13:e0205074.

33. Delkash-Roudsari S, Chicas-Mosier AM, Goldansaz SH, Talebi-Jahromi K, Ashouri A, Abramson Cl. Assessment of lethal and sublethal effects of imidacloprid, ethion, and glyphosate on aversive conditioning, motility, and lifespan in honey bees (Apis mellifera L.). Ecotoxicol Environ Saf. 2020:204:111108.

34. Farina WM, Balbuena MS, Herbert LT, Mengoni Goñalons C, Vázquez DE. Effects of the herbicide glyphosate on honey bee sensory and cognitive abilities: individual impairments with implications for the hive. Insects. 2019;10:354.

35. Herbert $L T$, Vázquez DE, Arenas A, Farina WM. Effects of field-realistic doses of glyphosate on honeybee appetitive behaviour. J Exp Biol. 2014;217:3457-64.

36. Balbuena MS, Tison L, Hahn M-L, Greggers U, Menzel R, Farina WM. Effects of sublethal doses of glyphosate on honeybee navigation. J Exp Biol. 2015;218:2799-805 
37. Faita MR, Cardozo MM, Amandio DTT, Orth Al, Nodari RO. Glyphosatebased herbicides and Nosema sp. microsporidia reduce honey bee (Apis mellifera L.) survivability under laboratory conditions. J Apic Res. 2020;59:332-42. https://doi.org/10.1080/00218839.2020.1736782.

38. Zhao H, Li G, Guo D, Wang Y, Liu Q, Gao Z, et al. Transcriptomic and metabolomic landscape of the molecular effects of glyphosate commercial formulation on Apis mellifera ligustica and Apis cerana cerana. Sci Total Environ. 2020;744:140819.

39. Howe CM, Berrill M, Pauli BD, Helbing CC, Werry K, Veldhoen N. Toxicity of glyphosate-based pesticides to four North American frog species. Environ Toxicol Chem. 2004;23:1928-38.

40. Gaupp-Berghausen M, Hofer M, Rewald B, Zaller JG. Glyphosate-based herbicides reduce the activity and reproduction of earthworms and lead to increased soil nutrient concentrations. Sci Rep. 2015;5:12886.

41. Mao Q, Manservisi F, Panzacchi S, Mandrioli D, Menghetti I, Vornoli A, et al. The Ramazzini Institute 13-week pilot study on glyphosate and Roundup administered at human-equivalent dose to Sprague Dawley rats: effects on the microbiome. Environ Health. 2018 [cited 2019 May 22]:17. Available from https://www.ncbi.nlm.nih.gov/pmc/articles/PMC5972442/.

42. Nosanchuk JD, Ovalle R, Casadevall A. Glyphosate inhibits melanization of Cryptococcus neoformans and prolongs survival of mice after systemic infection. J Infect Dis. 2001;183:1093-9.

43. Smith DFQ, Camacho E, Thakur R, Barron AJ, Dong Y, Dimopoulos G, et al. Glyphosate inhibits melanization and increases susceptibility to infection in insects. PLoS Biol. 2021;19:e3001182.

44. Baffoni L, Alberoni D, Gaggì F, Braglia C, Stanton C, Ross PR, et al. Honeybee exposure to veterinary drugs: how is the gut microbiota affected? Microbiol Spectr. 2021;9:e00176-e221.

45. Powell JE, Carver Z, Leonard SP, Moran NA. Field-realistic tylosin exposure impacts honey bee microbiota and pathogen susceptibility, which is ameliorated by native gut probiotics. Microbiol Spectr. 2021;9:e00103-21.

46. ReybroeckW, Daeseleire E, De Brabander HF, Herman L. Antimicrobials in beekeeping. Vet Microbiol. 2012;158:1-11.

47. Lohman BK, Weber JN, Bolnick DI. Evaluation of TagSeq, a reliable lowcost alternative for RNAseq. Mol Ecol Resour. 2016;16:1315-21.

48. Steele MI, Motta EVS, Gatu T, Martinez D, Moran NA. The gut microbiota protects bees from invasion by a bacterial pathogen. Microbiol Spectr. 2021 [cited 2021 Jan 26]; Available from http://www.onlinelibrary.wiley. com/doi/abs/10.1002/9781119583417.notes.

49. Murdoch SL, Trunk K, English G, Fritsch MJ, Pourkarimi E, Coulthurst SJ, The opportunistic pathogen Serratia marcescens utilizes type VI secretion to target bacterial competitors. J Bacteriol. 2011:193:6057-69.

50. Burritt NL, Foss NJ, Neeno-Eckwall EC, Church JO, Hilger AM, Hildebrand $\mathrm{JA}$, et al. Sepsis and hemocyte loss in honey bees (Apis mellifera) infected with Serratia marcescens strain Sicaria. PLoS ONE. 2016;11:e0167752.

51. Raymann K, Coon KL, Shaffer Z, Salisbury S, Moran NA. Pathogenicity of Serratia marcescens strains in honey bees. MBio. 2018;9:e01649-18.

52. Vázquez DE, Latorre-Estivalis JM, Ons S, Farina WM. Chronic exposure to glyphosate induces transcriptional changes in honey bee larva: a toxicogenomic study. Environ Pollut. 2020;261:114148.

53. Yang X, Cox-Foster DL. Impact of an ectoparasite on the immunity and pathology of an invertebrate: evidence for host immunosuppression and viral amplification. PNAS Natl Acad Sci. 2005:102:7470-5.

54. Aronstein KA, Murray KD, Saldivar E. Transcriptional responses in honey Bee larvae infected with chalkbrood fungus. BMC Genomics. 2010;11:391.

55. Cullen TW, Schofield WB, Barry NA, Putnam EE, Rundell EA, Trent MS, et al. Antimicrobial peptide resistance mediates resilience of prominent gut commensals during inflammation. Science. 2015;347:170-5.

56. Buchon N, Silverman N, Cherry S. Immunity in Drosophila melanogasterfrom microbial recognition to whole-organism physiology. Nat Rev Immunol. 2014;14:796-810.

57. Diamond G, Beckloff N, Weinberg A, Kisich KO. The roles of antimicrobial peptides in innate host defense. Curr Pharm Des. 2009;15:2377-92.

58. Vannette RL, Mohamed A, Johnson BR. Forager bees (Apis mellifera) highly express immune and detoxification genes in tissues associated with nectar processing. Sci Rep. 2015:5:16224.

59. Cerenius L, Söderhäll K. The prophenoloxidase-activating system in invertebrates. Immunol Rev. 2004;198:116-26.

60. Ramsden CA, Riley PA. Tyrosinase: the four oxidation states of the active site and their relevance to enzymatic activation, oxidation and inactivation. Bioorg Med Chem. 2014;22:2388-95.
61. González-Santoyo I, Córdoba-Aguilar A. Phenoloxidase: a key component of the insect immune system. Entomol Exp Appl. 2012;142:1-16.

62. Rok J, Buszman E, Delijewski M, Otręba M, Beberok A, Wrześniok D. Effect of tetracycline and UV radiation on melanization and antioxidant status of melanocytes. J Photochem Photobiol B Biol. 2015;148:168-73.

63. Beberok A, Buszman E, Wrześniok D, Otręba M, Trzcionka J. Interaction between ciprofloxacin and melanin: the effect on proliferation and melanization in melanocytes. Eur J Pharmacol. 2011;669:32-7.

64. Beberok A, Wrześniok D, Otręba M, Miliński M, Rok J, Buszman E. Effect of norfloxacin and moxifloxacin on melanin synthesis and antioxidant enzymes activity in normal human melanocytes. Mol Cell Biochem. 2015:401:107-14.

65. Thompson HM, Levine SL, Doering J, Norman S, Manson P, Sutton P, et al. Evaluating exposure and potential effects on honeybee brood (Apis mellifera) development using glyphosate as an example. Integr Environ Assess Manag. 2014;10:463-70.

66. Andrews S. FastQC: a quality control tool for high throughput sequence data. http://www.bioinformatics.babraham.ac.uk/projects/fastqc/. 2010 [cited 2021 Jan 17]. Available from http://www.bioinformatics.babraham. ac.uk/projects/fastqc/.

67. Bushnell B. BBMap: a fast, accurate, splice-aware aligner. Lawrence Berkeley National Lab. (LBNL), Berkeley, CA (United States); 2014 Mar. Report No.: LBNL-7065E. Available from https://www.osti.gov/biblio/1241166bbmap-fast-accurate-splice-aware-aligner.

68. Dobin A, Davis CA, Schlesinger F, Drenkow J, Zaleski C, Jha S, et al. STAR: ultrafast universal RNA-seq aligner. Bioinformatics. 2013;29:15-21.

69. Love MI, Huber W, Anders S. Moderated estimation of fold change and dispersion for RNA-seq data with DESeq2. Genome Biol. 2014;15:550.

70. R Core Team. R: a language and environment for statistical computing. Vienna, Austria; 2013. Available from http://www.R-project.org/.

71. Jeon JH, Moon K, Kim Y, Kim YH. Reference gene selection for qRT-PCR analysis of season- and tissue-specific gene expression profiles in the honey bee Apis mellifera. Sci Rep. 2020;10:13935.

72. Ahmed M, Kim DR. pcr: an R package for quality assessment, analysis and testing of qPCR data. PeerJ. 2018;6. Available from https://www.ncbi.nlm. nih.gov/pmc/articles/PMC5858653/.

73. Bolyen E, Rideout JR, Dillon MR, Bokulich NA, Abnet CC, Al-Ghalith GA, et al. Reproducible, interactive, scalable and extensible microbiome data science using QIIME 2. Nat Biotechnol. 2019;37:852-7.

74. Martin M. Cutadapt removes adapter sequences from high-throughput sequencing reads. EMBnet.journal. 2011;17:10-2.

75. Callahan BJ, McMurdie PJ, Rosen MJ, Han AW, Johnson AJA, Holmes SP. DADA2: high-resolution sample inference from Illumina amplicon data. Nat Methods. 2016;13:581-3.

76. Bokulich NA, Kaehler BD, Rideout JR, Dillon M, Bolyen E, Knight R, et al. Optimizing taxonomic classification of marker-gene amplicon sequences with QIIME 2's q2-feature-classifier plugin. Microbiome. 2018;6:90.

77. Borsuk G, Ptaszyńska AA, Olszewski K, Domaciuk M, Krutmuang P, Paleolog J. A new method for quick and easy hemolymph collection from Apidae adults. PLoS ONE. 2017;12:e0170487.

\section{Publisher's Note}

Springer Nature remains neutral with regard to jurisdictional claims in published maps and institutional affiliations. 